\title{
Urdimento
}

\section{AS APARÊNCIAS MUTANTES DE UM CORPO QUE SE DESNUDA}

\author{
Vera Collaço ${ }^{1}$
}

\section{Resumo}

Pretendo nesse artigo apontar para uma análise das significações que o corpo feminino adquiriu ou foi adquirindo no Teatro de Revista brasileiro no final do século XIX, quando este gênero consegue firmar-se em nosso teatro, até sua desintegração, enquanto gênero específico, no final da década de 1960; e através deste percurso, analisar a participação do corpo feminino revisteiro como definidor do sujeito, da sua história, como construtor de identidades sociais

Palavras-chave: feminino, revista, corpo.

Ao partir do pressuposto, tal como colocado por Ana Cláudia de Oliveira e Káthia Castilho (2008:7), de que "o corpo se altera em forma e sentidos ao longo da história e varia também de acordo com a cultura na qual se insere", percebemos que até o final do século XIX, no mundo ocidental, ao corpo era atribuído um papel secundário, contudo, como bem observa JeanJacques Courtine (2006:7), na "virada do século, [...], a relação entre o sujeito e o seu corpo começou a ser definida em outros termos". Nesta etapa rompese a linha limite entre corpo e espírito e com isso o século XX, ainda com as palavras de Courtine (2006:7), "restaurou e aprofundou a questão da carne, isto é, do corpo animado".

Coube, portanto, ao século XX a invenção teórica do corpo. Corpo este que passou a ligar-se ao inconsciente, e foi amarrado ao sujeito e inserido nas formas sociais da cultura. Esse século conheceu, pela primeira vez na história, uma superexposição obsessiva do corpo íntimo e sexuado. Assim, viu-se afrouxar
1Professora efetiva do Centro de Artes/ Universidade do Estado de Santa Catarina, com atividades no Programa de Pós-Graduação em Teatro (PPGT) e na graduação em teatro; Doutora em História Cultural. Desde 2005 vem pesquisando sobre o Teatro de Revista em Santa Catarina e no Brasil, sendo que este artigo resulta do trabalho desenvolvido nesta pesquisa. 


\section{Urdimento}

as "coerções e disciplinas herdadas do passado", bem como o fortalecimento e a "legitimidade outorgada ao prazer", sem que com isso, evidentemente, tenham desaparecido por completo as tensões "entre desejos do corpo sexuado e normas de controle social”, especialmente na primeira metade do século XX.

Ao partir da compreensão do acima exposto, das transformações perceptíveis do corpo, pretendo nesse artigo apontar para uma análise das significações que este corpo adquiriu ou foi adquirindo no Teatro de Revista brasileiro desde o final do século XIX, quando este gênero consegue firmarse em nosso teatro, até sua desintegração, enquanto gênero específico, no final da década de 1960; e através deste percurso, analisar a participação do corpo feminino revisteiro como definidor do sujeito, da sua história, como construtor de identidades sociais.

Para tanto, o recorte estabelecido neste trabalho diz respeito ao corpo feminino. E ao corpo feminino no Teatro de Revista brasileiro. E do corpo feminino, deste teatro, focalizo minha atenção apenas no corpo das vedetes e das girls, ou coristas como eram denominadas estas dançarinas até a década de 1920.

No momento atual da pesquisa, que resulta neste artigo, pretendo interligar este corpo feminino revisteiro com o "recuo do pudor" - expressão cunhada por Anne-Marie Sohn (2006:109) -, ou seja, abordar como o afrouxamento das coerções e o fortalecimento da visibilidade, exposição e do prazer proporcionado pelo corpo sexuado e sensual, foram apropriadas e re-trabalhadas no palco revisteiro através das suas vedetes e girls. E com isso entender o espanto e censura, pela ruptura das normas, o desejo e o maravilhoso, pela exposição do corpo feminino, e por fim, a coisificação, com um corpo explorado apenas como produto barato, tal como é perceptível na história deste gênero teatral no Brasil. Tenho, neste caso, por hipótese que estas mulheres, as vedetes e as girls, podem ser pensadas como o elemento visível destas transformações, ou seja, há uma relação de co-dependência entre corpo e ambiente. E, desta forma, quando o corpo muda, dizia Walter Benjamin (apud KATZ, 2008:69), tudo já foi transformado. E, como conseqüência, as reações ao desnudamento do corpo das vedetes e girls, a apropriação, por parte destas artistas, de seu próprio corpo para o prazer e a sensualidade, servia de reverberação máxima ao que se percebia no corpo social.

Assim, neste artigo apresento as interligações deste corpo revisteiro feminino com a construção do corpo feminino que se espraiava no social, desde o final do século XIX e ao longo de todo o século XX. Observo, inicialmente, que o Teatro de Revista enquanto espetáculo ligeiro, que mistura prosa e verso, música e dança, têm por proposição colocar no palco os fatos da atualidade através do uso da paródia, da zombaria, do burlesco, do sensual e do sexual não 
explicitado, mas insinuado através de duplo sentido, do jogo, da teatralidade. Chamo a atenção que para este gênero teatral é, ou era, fundamental o diálogo com o momento presente, este "presentismo", que quase pode ser definido como o elemento central da estética revisteira, é, ou era, o ingrediente significativo para a compreensão de algumas de suas convenções, seja nas caricaturas vivas, nas paródias, nas críticas sutis ou explicitas, colocadas no palco, e capazes de provocar imediatas conexões com sua platéia. Nesta perspectiva, de trazer para o palco os fatos significativos do contexto imediato, se encontra um dos elementos vitais e fundamental da estabelecida cumplicidade entre palcoplatéia tão perceptível nas narrativas dos partícipes, na sua dramaturgia e mesmo nas fotografias e caricaturas desta prática teatral.

$\mathrm{Na}$ sua própria definição tal como apresenta Neyde Veneziano (2006:34) destaca-se esta percepção do presente: a revista é "uma resenha dos acontecimentos, passando em revista os fatos da atualidade". Salvyano (1991:6) explicita ainda mais a ligação com o presente ao definir a Revista como um gênero que tem por função "comentar a realidade cotidiana - com acompanhamento musical”. Na própria denominação do gênero Revista, Re-Vista, está explicito o seu objeto temático, ou seja, passar a vista sobre algo acontecido ou que está acontecendo, rever ou ver novamente. $\mathrm{O}$ acontecido se referia sempre ao ano anterior, eram as chamadas Revistas de Ano. Revista de Ano foi à primeira formatação deste gênero teatral, originário da França na segunda metade do século XIX, e que teve sua primeira versão no Brasil em 1859 com As Surpresas do Sr. José da Piedade, de Justino de Figueiredo Novais. Este gênero somente firma-se no Brasil a partir da estréia de O Mandarim, em 1884, que passava em revista o ano de 1883, de Arthur Azevedo e Moreira Sampaio. A partir da década de 1920 este tipo - Revista de Ano - entra em desuso e passamos a encontrar na denominada Revista Clássica, cuja base é a referencialidade ao presente imediato, ou seja, ao cotidiano que cerca as pessoas na sua atualidade.

É no presentismo, na referencialidade ao seu contexto imediato que está à riqueza e a dificuldade para entendermos este gênero teatral na nossa atualidade. Na leitura contemporânea do texto revisteiro perde-se muito do referencial e das sutilezas, às vezes nem tão sutis para sua época, paródicas e caricaturais. Mas, mesmo com estas barreiras, estamos diante de um gênero teatral que permite uma leitura, ou re-leitura, do passado como talvez nenhum outro o possibilite. Flora Süssekind (1986) chega a denominar as Revistas, no seu caso as Revistas de Ano, e que eu me aproprio e o estendo a todo este gênero, como mapas, painéis, panoramas. Mapas é uma imagem do significado da Revista importante para meu raciocínio, pois faz com que a Revista aponte caminhos que estão sendo construídos simultaneamente no social e no palco. Só que no palco estamos no reino da ficção, mas as atrizes, as vedetes e as girls, são pessoas 


\section{Urdimento}

de carne e osso, ou seja, possuem corpo, e, conseqüentemente, estão sujeitas a coerções e a desejos de adequar-se aos novos tempos. Estas personagens apresentam ou representam não apenas seus próprios desejos de adequar-se à modernidade de seu tempo, mas também devem ser passíveis de serem lidas, pelo seu espectador, como um referencial de modernidade dos novos tempos. Elas fazem avançar a fronteira do pudor mais rapidamente do que no social, expõem-se mais à visibilidade, permitem-se mais intensamente a exposição do prazer de possuir corpos bem delineados e submetê-los a apreciação do outro.

Para atender ao objeto aqui proposto, analiso o corpo no Teatro de Revista brasileiro em três momentos de sua trajetória, correspondentes aos processos sociais e culturais de transformações nas relações do individuo e do coletivo com o corpo, que abaixo procuro detalhar e fazer as devidas inter-relações.

\section{Um corpo na aparência vestido}

Em concordância com as palavras de Oliveira (2008:93) entendemos que:

A roupa não veste um suporte vazio, o corpo. Ao contrário, sendo carregado de sentido na sua malha de orientações, este interage com as direções, formas, cores, cinetismo e materialidades da roupa e atua de variados modos nas suas configurações, tomadas de posições $e$ de movimentação.

O corpo, aparentemente super-vestido, ou seja, um corpo coberto pela roupa, corpo que pouco expõe a pele, a dita "nudez corporal", domina o período denominado de Revista de Ano, na qual o trocadilho e a possível alusão ao sensual e sexual estava colocado na palavra e não no gesto, portanto, não estava no corpo, e muito menos no corpo feminino. Neste período, que pode ser compreendido entre 1884, esmaecendo a partir de 1910 e findo na década de 1920, deve-se ressaltar que a força do palco estava centrada na figura masculina, especialmente nos atores cômicos. Podemos afirmar que a vedete da Revista de Ano era o comediante. A força do espetáculo estava centrada no texto e na suas possibilidades de provocar o riso por meio da performance cômica dos atores.

No palco, quem dava vida e consistência aos tipos esquemáticos da revista, bem como aos da opereta e da mágica, eram os atores cômicos, especialistas da comunicação imediata com a platéia. Cantavam com a pouca voz que tinham, sem aperfeiçoamento musical, mas sabiam extrair do texto a salacidade, o duplo sentido sexual que os autores haviam disseminado no texto, para que explodissem na hora certa em cena, graças aos olhares maliciosos, aos gestos e inflexões equívocos dos interpretes. Nada era dito com todas as letras, tudo ficava subtendido (PRADO, 1999:167). 
Nesta fase revisteira o corpo das mulheres, ainda que considerado exposto para o período, estava bastante protegido. As girls, que ainda se denominavam de coristas, usavam meias grossas, na cor da pele. Os decotes eram discretos, e as vedetes usavam poucos adornos chamativos e menos ainda apelativos ou de duplo sentido. Assim, com as palavras de Oliveira (2008:93), percebemos que "o corpo vestido mostra os modos de o sujeito estar no mundo, a sua presença", referenciando "as aparências do sujeito e algo de sua essência, o corpo vestido dá a ver". Portanto, essas vedetes e girls, mesmo com um complemento protegendo seu corpo, estavam sujeitas a uma leitura de desnudamento por parte de seu potencial espectador, que ampliava seu despir-se restrito aos braços e tornozelos, e a um pequeno decote. Embora transgressora para os moralistas de plantão, mais pela palavra do que pela cena, esta revista margeava os limites da moral vigente.

As danças desenvolvidas nesta fase da Revista eram improvisadas e dependiam mais da indumentária, com algum apelo visual, do que da uniformidade do conjunto das coristas e dançarinas. Ou como bem o coloca Salvyano Paiva:

No século e início do século $X X$ as fotografias nos mostram "coristas gorduchinhas e desengonçadas". O trabalho de coristas "dependia da indumentária farfalhante" e se caracterizava pela "inexistência de um padrão de uniformidade. [...] Até porque a coreografia era, como tudo o mais, improvisada. Raras vezes as marcações dançantes constituíam parte integrante da ação dos esquetes da peça; ao invés, serviam mais de introdução ou conclusão, ou apenas ensemble para o desempenho de astros e estrelas". (PAIVA, 1999: 21)

O corpo, fosse da "estrela" ou das "coristas"- "girls", estava protegido por "fantasias" que não expunham o corpo no seu todo, mas estas roupas eram construtoras de outras fantasias, vestido ou com pequenas partes despidas, este corpo estimulava um ir além do limite estabelecido no social. Estas mulheres possuíam um corpo de acordo com o tempo em que estavam inseridas, por isso serem "gorduchinhas", era um corpo no qual a magreza extrema passava longe de uma estética de beleza. E a visão de um corpo totalmente despido podia despertar mais anseios do que prazer. Assim, amostras de partes desnudas do corpo, um avanço enorme para o período, poderia estimular e despertar desejos ocultos, e conter a possibilidade de despi-los mentalmente no limite privado de um quarto ou outro espaço mais íntimo do individuo, onde a censura e a castração momentaneamente fossem banidos. Por isso, podemos dizer que temos no período da Revista de Ano um corpo na aparência vestido, mas que se despe, ou que pode ser despido pelo imaginário do potencial espectador, devido aos indícios de desnudamento corporal e gestual das atrizes. 


\section{Urdimento}

\section{O corpo na aparência despido}

De acordo com Anne-Marie Sohn (2006:110) "o recuo do pudor", esboçado desde a Bella Époque, "vai se acelerando no período entre-guerras e se difunde durante os Trinta Gloriosos”. Neste período temos o início da virada no Teatro de Revista. Na primeira década do século XX a Revista de Ano começa a ser substituída pela Revista, depois denominada de Revista Clássica. Com isso vai se abandonando o tênue fio de enredo, e a música e a dança ganham mais espaço, e conseqüentemente o corpo avança e domina a cena.

Ainda com as palavras de Anne-Marie Sohn (2006:132) observa-se que "durante séculos a sexualidade foi mantida sob silencio ou despachada para o registro de coisas 'sujas' e pecaminosas”. Era preciso, portanto, retirar a sexualidade do silencio e da vergonha. Legitimar o prazer. E conseqüentemente deveria ocorrer a dessacralização do corpo feminino. E mais uma vez, me parece, a revista apresenta com antecipação este novo corpo feminino, que começa a aparecer com sua veste original, qual seja, a pele que reveste o corpo, a sua primeira vestimenta.

Como afirma Délson Antunes (2002:49) na década de 1920 "o teatro ligeiro embarcava na folia. Consolidava-se definitivamente o grande período das revistas-carnavalescas, que impulsionou a popularidade do gênero". O predomínio carnavalesco não implicava somente o voltar-se para as musicas e marchas destinadas a folia do carnaval. Implicava, também, e isso é muito significativo, uma nova relação com o corpo, com este corpo que dançaria de forma diferenciada, com cadência e um acento todo particular das "cadeiras", no rebolado feminino.

O corpo feminino que dança não se faz mais de improviso. As coristas, após 1920, passam a ter apoio de coreógrafos profissionais, entram em contato com o balé clássico e com as danças modernas. E, no corpo de baile, havia bailarinos franceses, poloneses, portugueses, argentinos. Todos trabalhando sob rígida disciplina, típica construção do pensamento moderno, que visa modelar, disciplinar tudo o que se refere ao corpo social, inclusive o corpo individual.

Duas companhias estrangeiras em tournée pelo Brasil foram significativas para alavancar o "recuo do pudor" na cena revisteira. Em 1922 esteve no Brasil a Companhia de Revista Ba-Ta-Clan, de Madame Rasimi (França), e em 1923 veio a Companhia Velasco, companhia espanhol de Teatro de Revista. Estas duas companhias mostraram aos produtores cariocas "a valorização da participação feminina nos espetáculos. As atrizes ganhavam terreno, com os seus nomes despontando nos cartazes como os primeiros nomes das companhias" (ANTUNES, 2002:54). Mas o avanço foi além: 
Entre as novidades importadas, adotou-se a suspensão das meias grossas que cobriam as pernas das coristas, abrindo caminho para o "nu artístico". O apelo erótico mais explícito ganhou força nos espetáculos. A nudez de seios e braços das francesas empolgou as platéias e logo foi copiado pelas artistas locais. (ANTUNES, 2002:54)

O palco começava a explorar o banho de mar, os maios, e como observa Salvyano Paiva (1999:212) "o corpo feminino começava a ser tratado como objeto estético digno de observação e não mais como santuário indevassável de virtudes vitorianas e de hipocrisia”. A partir da década de 1930 a praia transforma-se em lugar de ócio e de lazer, e "convida a expor o corpo desnudo para apresentar um bronzeado perfeito, símbolo agora de boas férias" (SOHN, 2006:110-111). A revista também explora em seus quadros a sensualidade corporal exposta nas areias das praias cariocas. Contudo, a exposição corporal tem seu preço, as "gorduchinhas e desengonçadas" coritas das décadas anteriores não tinham mais condição de ocupar a cena revisteira, a não ser em papéis cômicos e caricaturais. Começava a era das vedetes, como Otília Amorim, Margarida Max, Aracy Cortes, e girls com corpos trabalhados através da dança, corpos que deviam provocar desejo e dar prazer à platéia na sua visibilidade.

É nos anos 1930 que a sexualidade não é mais somente sugerida, mas apresentada em cena, tanto nos filmes como nos cartazes: sedutoras em combinação e ligas, amantes desfalecidas sobre a cama, beijos cheios de paixão, tudo isso como prova do desejo e do prazer (SOHN, 2006:113).

O Teatro de Revista caminha a passos largos para o luxo e a exposição da beleza feminina através de corpos cada vez mais trabalhados e magros. Pois, observa SOHN (2006:111) ao referir-se ao novo corpo em construção na década de 1930, no qual incluímos o corpo da atriz revisteira: "Desde então, com efeito, que homens e mulheres não podem mais trapacear com o corpo, os cânones da beleza física se mostram muito exigentes. A partir da Bella Époque, o modelo do homem e da mulher magros e longilíneos predomina". Era preciso perder peso: "Leve e solto, diziam os conselhos de beleza; o corpo ganharia em charme, juventude e velocidade. Não demoraria muito para que a gordura se transformasse em sinônimo de lentidão, atraso" (SANT'ANNA, 2008:62).

E como coloca Neyde Veneziano (2006:259) a beleza e o luxo implicaram em cenas apoteóticas onde não faltavam cascatas. "Havia cascatas de fumaça, cascatas de espuma, cascatas de água, cascatas de mulheres”. O corpo exposto tinha que ser, portanto, bonito e escultural. 


\section{Urdimento}

E, para garantir a exuberância das vedetes, Walter Pinto criou uma escada gigante. Girls e vedetes tinham que chegar ao topo e entrar nela através dos camarins do primeiro andar para descer seus degraus, um a um, sem olhar para o chão. Conta-se que Walter Pinto fazia as coitadas descer, em média, trinta vezes por dia, até que conseguissem fazê-lo com graciosidade e de cabeças erguidas! Condição básica para ser uma vedete. E valia a pena! O publico delirava e a revista ditava moda.

A rígida censura do Estado Novo fez a revista investir mais e mais no apelo visual e na beleza dos corpos femininos, realçados pelas luzes, brilhos e lantejoulas. O nu artístico e estático começa a ser permitido. Mas, a força do espetáculo se mantém pelo trabalho artístico das vedetes, das girsl e dos grandes cômicos.

Nos palcos de exposição do sujeito, integram a cena não somente os modelos prescritos de corpo mas também os prescritos para a indumentária, e os tipos de articulação, que o sujeito realiza no processamento do corpo vestido, vão talhar a construção de sua aparência, na qual intervêm a sua concepção de mundo, de vida, seus anseios e seus valores (OLIVEIRA, 2008:94).

Estas estrelas e girls expressavam, através deste despir-se, um comportamento pela linguagem da não-roupa, dos adereços apelativos, de cores exuberantes, o corpo doava-se por inteiro, numa afronta a um pudor deslocado de uma sociedade despudoradamente carnavalesca, mas cuja permissão para tanto desnudamento ainda estava restrito a algumas esferas do social, especialmente para além da fronteira do real-social, na fronteira do ficcional, e que poderia ser avançada para a realidade, mas com o devido deslocamento da palavra atriz para meretriz.

\section{O corpo nu?!}

Como observa Sohn (2006:114) "os limiares da tolerância, no entanto, evoluem rapidamente nos anos 1950". A hipocrisia é deixada de lado. O cinema, as artes imagéticas, a Revista passam a explorar o corpo em toda a sua sexualidade e nudez. No final da década de 1950, expõe Sant’Anna: "a publicidade começou a explorar cenas em que a mulher se abraçava e fechava os olhos, expandia uma gargalhada e se mostrava tomada pela alegria de viver" (2008:81).

Este processo de desnudamente, das vedetes e girls no Teatro de Revista, parece coincidir com o princípio de desmoronamento deste gênero teatral no Brasil, pelo menos é o que nos apontam os estudiosos mais empenhados em compreender o significado e importância do Teatro de Revista 
brasileiro. Na década de 1950, diz Antunes (2002:124): "as grandes vedetes se tornavam musas. Na falta de outros atrativos, o espetáculo tomava o caminho da exploração desenfreada da sensualidade feminina” .

No princípio os nus, eram feitos quase sempre por "estrangeiras", ficavam localizados no fundo do palco, no alto, às vezes pendurados. As girls nuas eram vistas de longe, usando apenas um tapa-sexo, e encobertas pela fumaça, pelas plumas e brilhos.

Neyde Veneziano (2006:277) observa que:

Foi nos anos 1960 que os nus começaram a avançar para o proscênio. Ao mesmo tempo que os corpos despidos investiam, em direção ao show de strip-tease, as mulheres vestidas, na platéia, recuavam. Revista era espetáculo assistido por famílias. Mudou o caráter e mudou, também, o público que a prestigiava.

A maioria dos estudiosos deste período aponta para a banalização do corpo e do sexo explicito, dominantes no Teatro de Revista a partir de 1960, como o responsável pelo fim deste gênero no teatro brasileiro. Indo numa espécie de contramão do que vinha ocorrendo no social. Visto que o longo processo de liberação do corpo, especialmente do corpo feminino, "esboçado desde o final do século XIX, mas reivindicado somente nos anos de 1960”, (SOHN, 2002: 132) não parece ser mais compatível com sua exposição na cena revisteira.

Isso nos leva a questionar: porque a excessiva exposição do corpo no Teatro de Revista implicaria na sua decadência? Que corpos estavam sendo expostos? O que houve com o espetáculo? E Neyde Veneziano aponta dois responsáveis pelo descaminho do gênero:

A primeira invasão foi a de um vírus que veio em série: stripteases teatralizados. Atacaram quase todas as salas que apresentavam teatro de revista. Os strip-teases teatralizados reduziram sensivelmente o espetáculo. O problema é que continuaram a chamar esses gêneros de revistas. Só que já não revia mais nada. A segunda invasão foi a da grosseria, responsável pela desintegração do gênero (no sentido estrutural, mesmo). O palavrão gratuito e o sexo quase explicito tomaram conta desses shows (VENEZIANO, 2006: 278).

Segundo a maioria dos estudiosos do Teatro de Revista a partir de 1960, mas desde 1950 já começa a despontar, a revista perdia sua força para a gratuidade da exposição física. O palavrão e a sexualização excessiva não deixou margem para a insinuação e a malícia que eram as características mais tradicionais da revista. 


\section{Urdimento}

Vários ingredientes podem ser responsáveis pelo desaparecimento do Teatro de Revista brasileiro, tais como a rígida censura do Regime Militar, de 1964 a 1985, o cansaço das parcerias jamais renovadas, novos veículos como a televisão que passam a sugar os artistas e a oferecer melhores condições de trabalho, a indigência de textos, etc. Mas, a insistência na questão sexual ronda a maioria dos estudiosos, diz Paiva (1999:632).

A vulgaridade e o apelo insistente à pornografia - forma diversionista e reforçadora do obscurantismo, típica da cultura de massa estimulada pelos regimes autoritários -, tudo contribuiu, particularmente depois de 1965, para deformar a revista, hoje relíquia arqueológica ou objeto de lazer passadista.

Acredito que todos os ingredientes acima tiveram parcela no abafamento desta linda história que foi o Teatro de Revista brasileiro. Poderíamos acrescentar a questão econômica, produzir Revista é muito caro. Apresentar um espetáculo de revista implica num grande elenco, figurinos em grande quantidade e alguns bastante caros para vestirem os corpos das vedetes; implica, também, em muitos cenários, mesmo que estes sejam telões, há necessidade de efeitos especiais, luzes, etc. Sem contar com uma orquestra ou um conjunto musical de qualidade. Os custos são enormes e difíceis de serem arcados por um público escasso e fugidio, como se tornou o público do teatro brasileiro a partir da década de 1960. Assim, não me parece que foram os corpos nus, a saturação do gênero ou a baixa qualidade dos textos que levaram a falência do Teatro de Revista no Brasil, e sim uma peculiar junção de fatores econômicos e estéticos, tal como a valorização excessiva de uma poética cênica dita moderna, e uma perda substancial do público que freqüentava o teatro. $\mathrm{O}$ afastamento deste público, de classe média e baixa, das casas de espetáculos tem a ver com as duas causas acima apontadas econômica e estética - mas, também, com a remodelação das cidades, a partir da década de 1960, que distanciou estes espaços teatrais em relação à moradia e trabalho deste público. Novos corpos, novos tempos. A vedete e as girls tornaram-se corpos do passado, seus corpos vestidos ou nus foram substituídos seus similares em nossa cotidianidade.

\section{Referências bibliográficas}

ANTUNES, Delson. Fora do Sério: Um panorama do Teatro de Revista no Brasil. Rio de Janeiro: Funarte, 2002.

COURTINE, Jean-Jacques. Introdução. In: CORBIN, Alain; COURTINE, Jean-Jacques e VIGARELLOI, Georges (direção). História do Corpo: As mutações do olhar: $O$ século XX. Petrópolis, RJ: Vozes, 2008. 
GREINER, Christine. A Moda como Reinvenção do Corpo, o Corpo como Reinvenção da Moda: Estratégias. In: OLIVEIRA, Ana Cláudia de e CASTILHO, Kathia. Corpo e Moda: por uma compreensão do contemporâneo. Barueri, SP: Estação das Letras e Cores, 2008.

KATZ, Helena. Por uma Teoria Crítica do Corpo. In: OLIVEIRA, Ana Cláudia de e CASTILHO, Kathia. Corpo e Moda: por uma compreensão do contemporâneo. Barueri, SP: Estação das Letras e Cores, 2008.

OLIVEIRA, Ana Cláudia de. Apresentação. In: OLIVEIRA, Ana Cláudia de e CASTILHO, Kathia. Corpo e Moda: por uma compreensão do contemporâneo. Barueri, SP: Estação das Letras e Cores, 2008.

PAIVA, Salvyano Cavalcanti de. Viva o Rebolado: Vida e Morte do Teatro de Revista Brasileiro. Rio de Janeiro: Nova Fronteira, 1991.

PRADO, Décio de Almeida. História Concisa do Teatro Brasileiro. São Paulo: Edusp, 1999.

SANT'ANNA, Denize Bernuzzi. Consumir é ser Feliz. In: OLIVEIRA, Ana Cláudia de e CASTILHO, Kathia. Corpo e Moda: por uma compreensão do contemporâneo. Barueri, SP: Estação das Letras e Cores, 2008.

SOHN, Anne-Marie. O Corpo Sexuado. In: CORBIN, Alain; COURTINE, Jean-Jacques e VIGARELLOI, Georges (direção). História do Corpo: As mutações do olhar: $O$ século XX. Petrópolis, RJ: Vozes, 2008.

SÜSSEKIND, Flora. As revistas de ano e a invenção do Rio de Janeiro. Rio de Janeiro: Nova Fronteira, 1986.

VEneZIAnO, Neyde. De Penas Para o Ar: Teatro de Revista em São Paulo. São Paulo: Imprensa Oficial, 2006. 


\section{NORMAS PARA PUBLICAÇÃO DE ARTIGOS}

A Revista Urdimento é uma publicação do Programa de PósGraduação em Teatro da Universidade do Estado de Santa Catarina e reúne artigos que contribuiem para a pesquisa na área das artes cênicas.

A Urdimento recebe as colaborações em fluxo contínuo que são analisadas pelo Conselho Editorial. As seguintes normas técnicas devem ser observadas para a publicação das contribuições.

1) Os artigos devem ter no mínimo 8 e máximo 12 laudas. Resenhas de livros entre 3 e 4 laudas. Os textos deverão ser digitados com letra Times New Roman, tamanho 12, com espaçamento 1,5 cm em Word para Windows (ou compatível).

2) Os colaboradores devem incluir dados especificando as atividades que exercem, a instituição (se for o caso) em que trabalham e dados básicos dos respectivos currículos.

3) Solicita-se clareza e objetividade nos títulos.

4) Os artigos devem vir acompanhados de resumo com no máximo de 6 linhas e 3 palavras-chaves, ambos com as respectivas traduções para o inglês.

5) O envio do artigo original implica na autorização para publicação, tanto na forma imprensa como digital da revista.

6) Notas explicativas serão aceitas desde que sejam imprescindíveis e breves. As citações no corpo do tex to que sejam superiores a 5 linhas devem ser digitadas em espaço simples com tamanho 10 em itálico. As citações no corpo do texto devem seguir a formatação (UDESC, 2008, p.1).

7) Todas as palavras em língua estrangeira devem estar em itálico.

8) As notas de rodapé devem ser apresentadas no fim de cada página e numeradas em algarismos arábicos. 
9) Caso os artigos incluam fotos, desenhos ou materiais gráficos da autoria de terceiros, é indispensável carta de autorização. O material deverá vir acompanho de legendas de identificação. O material gráfico deve ser reduzido ao mínimo indispensável, em formato JPG e com resolução de 300 dpi, enviadas em arquivos separados do texto. Somente serão publicadas imagens em preto e branco.

10) O material para a publicação deverá ser encaminhado em duas vias impressas e uma em formato digital (programa word) para o e-mail urdimento@udesc.br aos cuidados da revista.

Endereço para correspondência e envio de colaborações:

\section{Revista Urdimento}

Programa de Pós-Graduação em Teatro - UDESC

Av. Madre Benvenuta, 1.907 - Itacorubi

88.035-001 - Florianópolis - SC

E-mail: urdimento@udesc.br

\section{Normas para citação de referência bibliográfica:}

\section{Livros}

SOBRENOME, Prenomes do autor. Título: subtítulo. edição. Local: editor, ano de publicação.

\section{Teses/ Dissertações/Monografias}

SOBRENOME, Prenomes do autor. Título: subtítulo. ano. $\mathrm{n}^{\circ}$ total de páginas.Tese, Dissertação ou Monografia (grau e área) - Unidade de Ensino, Instituição, Local e ano.

\section{Artigos de periódicos na internet}

SOBRENOME, Prenomes do autor. Título do artigo. Título da Revista, local, volume, número, páginas do artigo, mês e ano de publicação. Notas. Disponível em: <http://www....> Acesso em: dia mês (abreviado) ano, hora: minutos.

\section{Artigos}

SOBRENOME, Prenomes do autor do artigo. Título do artigo. Título da Revista, local, volume, número, páginas do artigo (inicial e final), mês e ano da publicação do artigo. 
Realização:

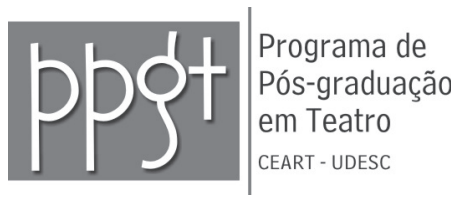

Programa de Pós-Graduação em Teatro

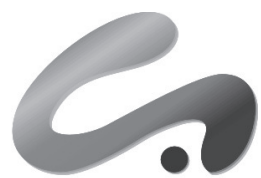

CEART

Centro de Artes 
Diagramação Editorial

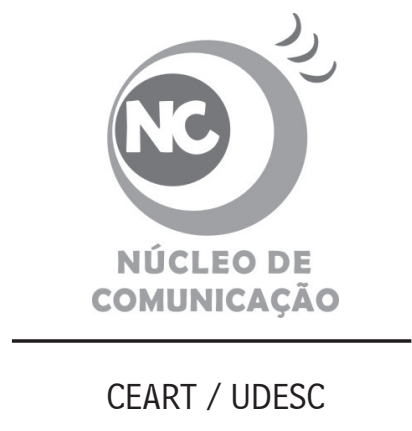

Este projeto editorial foi criado eletronicamente utilizando o software Adobe In Design CS3. As famílias tipográficas Bell MT e BellCent são utilizadas em toda esta revista. 